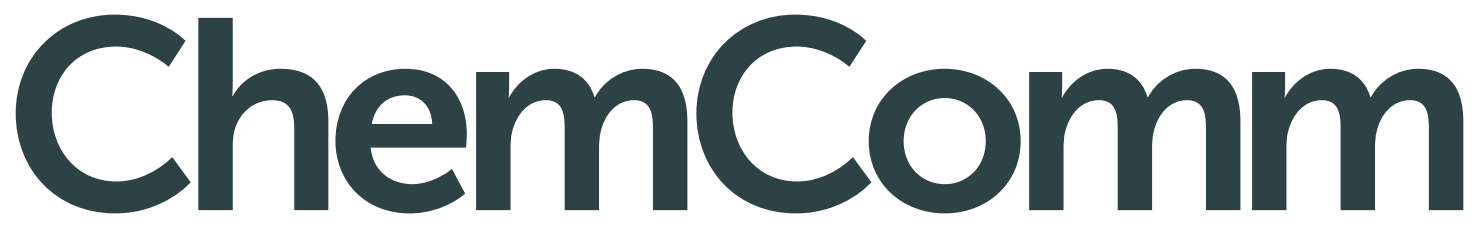

Chemical Communications www.rsc.org/chemcomm

$\times$
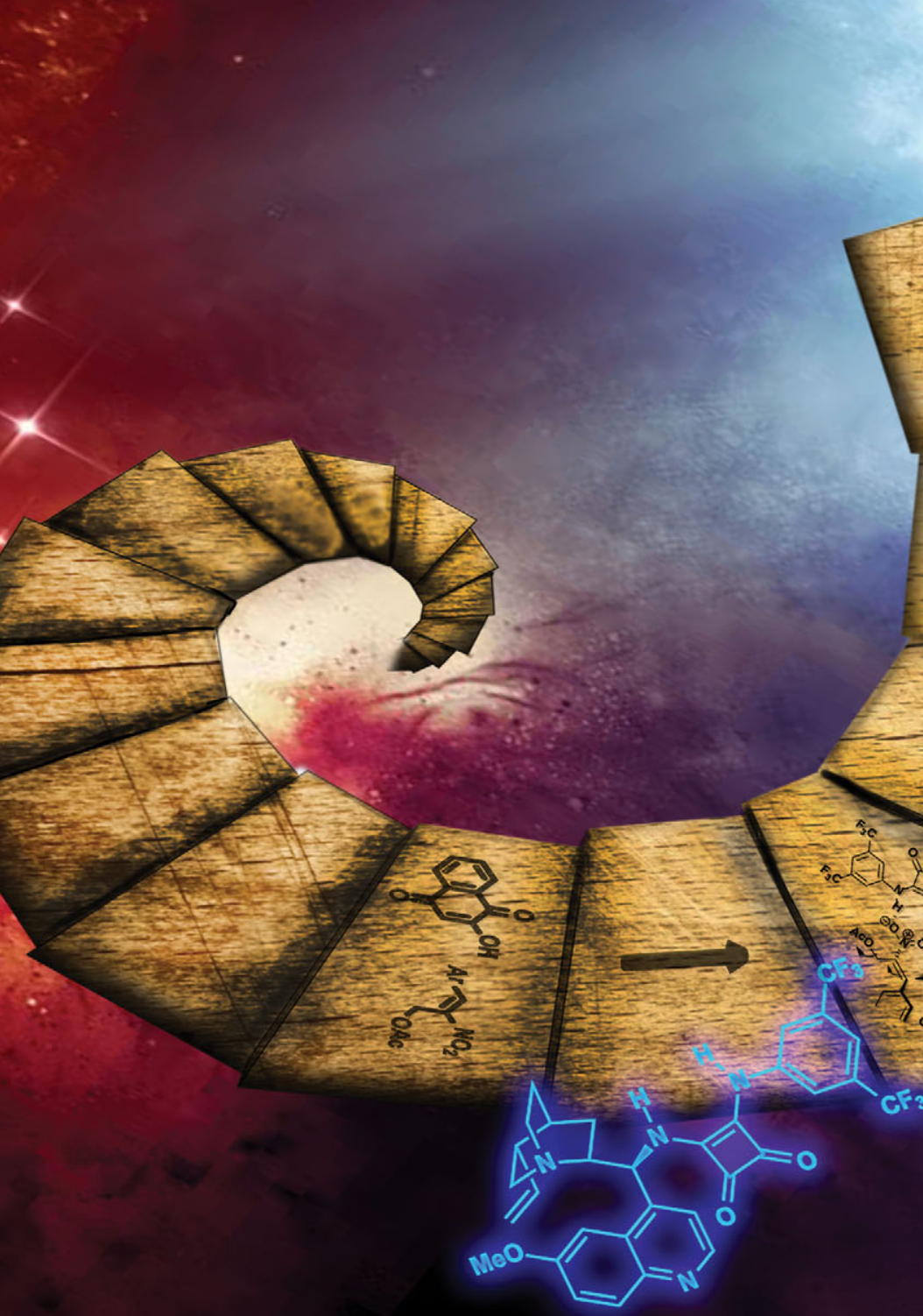

$\times$

se. 23

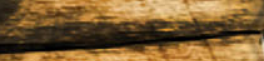

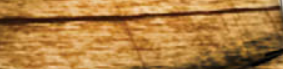

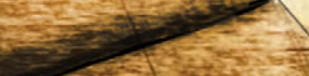
Setic

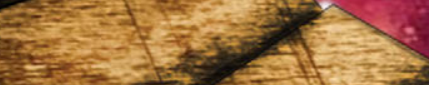
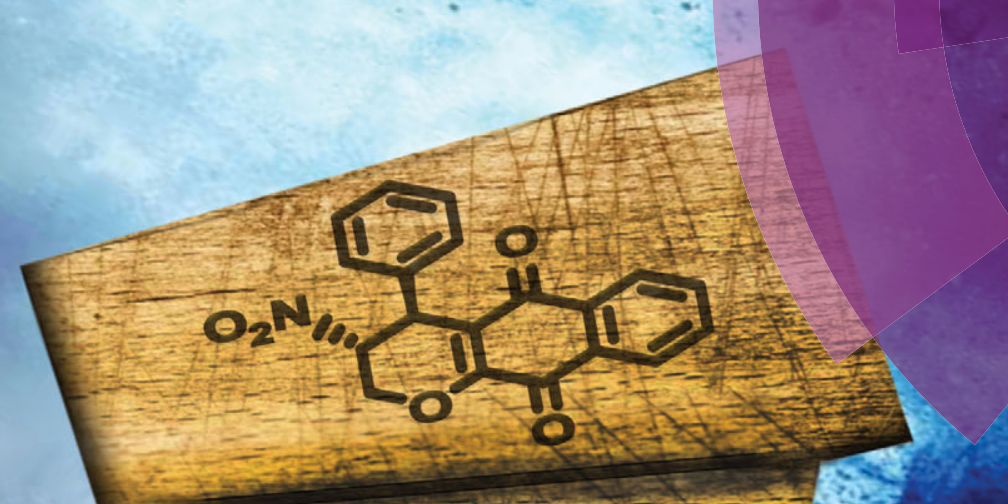
Cite this: Chem. Commun., 2014, 50, 6973

Received 27th March 2014, Accepted 29th April 2014

DOI: $10.1039 / c 4 c c 02279 c$

www.rsc.org/chemcomm

\section{Chiral squaramide-catalyzed asymmetric synthesis of pyranones and pyranonaphthoquinones via cascade reactions of 1,3-dicarbonyls with Morita-Baylis-Hillman acetates of nitroalkenes $\uparrow$}

\author{
Divya K. Nair, ${ }^{a}$ Rubem F. S. Menna-Barreto, ${ }^{b}$ Eufrânio N. da Silva Júnior, ${ }^{* c}$ \\ Shaikh M. Mobin ${ }^{d}$ and Irishi N. N. Namboothiri*a
}

\begin{abstract}
Cascade reactions of 1,3-dicarbonyls with Morita-Baylis-Hillman acetates of nitroalkenes using a quinine derived chiral squaramide organocatalyst led to the formation of pyranones and pyranonaphthoquinones in good to excellent yields and high diastereoand enantioselectivities. Representative examples of the reaction scale-up with a much lower catalyst loading without an appreciable loss of selectivities and synthetic transformations of the products are also reported here. The compounds described herein for the first time were evaluated against the infective bloodstream form of Trypanosoma cruzi, the etiological agent of Chagas disease, since the structures are related to bioactive $\alpha$-lapachones.
\end{abstract}

Naturally occurring naphthoquinones are widely distributed in the plant kingdom, exhibit redox properties and are involved in processes such as photosynthesis and electron transfer reactions. ${ }^{1}$ These compounds exhibit several activities against various diseases, e.g. Chagas disease, caused by the protozoan Trypanosoma cruzi, which affects approximately eight million individuals in Latin America. ${ }^{1,2}$ Pyranonaphthoquinones, in particular, display anticancer properties, besides being active against bacteria, fungi and mycoplasmas. ${ }^{3}$

Although $\alpha$-lapachones (e.g. Fig. 1) inherently possess weaker trypanocidal activity, ${ }^{1}$ structural modifications could lead to enhanced activity. ${ }^{4}$ Moreover, $\alpha$-lapachones exhibit a variety of other biological activities such as anti-tumor, ${ }^{5}$ anti-parasite (Leishmania), ${ }^{6}$ and mosquito cytochrome P450 enzyme inhibitory properties, ${ }^{7}$

\footnotetext{
${ }^{a}$ Department of Chemistry, Indian Institute of Technology Bombay, Mumbai 400 076, India. E-mail: irishi@iitb.ac.in

${ }^{b}$ Oswaldo Cruz Institute, FIOCRUZ, Rio de Janeiro, RJ, 21045-900, Brazil

${ }^{c}$ Institute of Exact Sciences, Department of Chemistry,

Federal University of Minas Gerais, Belo Horizonte, MG, 31270-901, Brazil. E-mail: eufranio@ufmg.br

${ }^{d}$ National Single-Crystal X-Ray Diffraction Facility,

Indian Institute of Technology Bombay, Mumbai 400 076, India

$\dagger$ Dedicated to Professor H. Ila on the occasion of her 70th birthday.

\$ Electronic supplementary information (ESI) available: Also complete experimental procedures, characterization data and copies of NMR spectra for all the new compounds. CCDC 993968. For ESI and crystallographic data in CIF or other electronic format see DOI: 10.1039/c4cc02279c
}
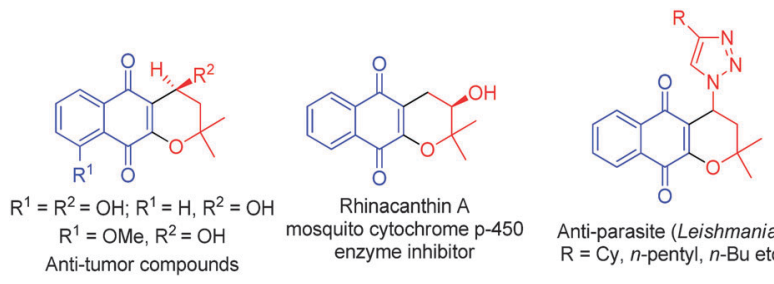

Anti-parasite (Leishmania)
$\mathrm{R}=\mathrm{Cy}, n$-pentyl, $n$-Bu etc

Fig. 1 Selected biologically active $\alpha$-lapachones.

to name a few. Recently, an asymmetric total synthesis of an $\alpha$-lapachone natural product rhinacanthin A (Fig. 1) has been reported. ${ }^{8}$

The diverse biological profiles of $\alpha$-lapachones inspired us to pursue their synthesis, especially in an asymmetric fashion. Although enantioselective conjugate addition of hydroxynaphthoquinone to different electron deficient alkenes, such as nitroalkenes, ${ }^{9}$ enones, ${ }^{10}$ unsaturated esters ${ }^{11}$ and phosphonates, ${ }^{12}$ in the presence of various chiral catalysts has been reported, there are only two such reactions, to our knowledge, that lead to $\alpha$-lapachones ${ }^{13}$ and neither uses Morita-Baylis-Hillman adducts of activated alkenes as the key substrates.

Recently, we reported the synthesis of furans, pyrans, ${ }^{14}$ and imidazopyridines ${ }^{15}$ as well as arenofurans ${ }^{16}$ via cascade $\mathrm{S}_{\mathrm{N}} 2^{\prime}$ intramolecular Michael addition of binucleophiles such as 1,3-dicarbonyl compounds, 2-aminopyridines and arenols, respectively, to Morita-Baylis-Hillman ( $\mathrm{MBH}$ ) acetates of nitroalkenes (e.g. 2, $\mathrm{E}=\mathrm{CO}_{2} \mathrm{Et}$, Scheme 1). Chen et al. also cleverly exploited the bielectrophilic nature of $\mathrm{MBH}$ acetates of nitroalkenes $2\left(\mathrm{E}=\mathrm{CO}_{2} \mathrm{Et}\right)$ for the synthesis of various carbocycles and heterocycles. ${ }^{17}$ The primary $\mathrm{MBH}$ acetate $2(\mathrm{E}=\mathrm{H})$, on the other hand, received less attention in such cascade reactions. ${ }^{18,19}$

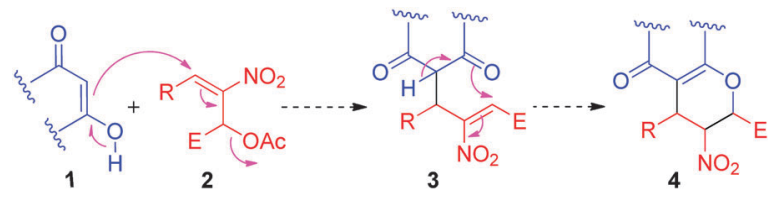

Scheme $1 \mathrm{~S}_{\mathrm{N}} 2^{\prime}$-intramolecular Michael addition. 
In the above scenario, we decided to employ 1,3-dicarbonyl compounds 1, including 2-hydroxy-1,4-naphthoquinone (lawsone), as binucleophiles in the reaction with primary $\mathrm{MBH}$-acetates of nitroalkenes $2(\mathrm{E}=\mathrm{H})$ in anticipation that the exclusive products would be pyrans 4 (Scheme 1). It appeared that such a cascade reaction in the presence of a suitable chiral catalyst would lead to enantioenriched pyrans and dihydropyranonaphthoquinones (lapachones). Therefore, we realized that the reaction sequence should begin with an enantioselective Michael addition of 1,3dicarbonyls 1 to $\mathrm{MBH}$ acetate $2(\mathrm{E}=\mathrm{H})$ in an $\mathrm{S}_{\mathrm{N}} 2^{\prime}$ manner to give intermediate $\mathbf{3}$, followed by a diastereoselective intramolecular oxa-Michael addition of 3 to afford the desired pyrans 4 . We hypothesized that this cascade reaction can be efficiently triggered by a chiral bifunctional catalyst which can simultaneously activate MBH-acetate $\mathbf{2}$ and deprotonate diketone $\mathbf{1}$.

In order to identify suitable reaction conditions for the asymmetric $\mathrm{S}_{\mathrm{N}} 2^{\prime}$-intramolecular Michael addition cascade, we have chosen dimedone $1 \mathrm{a}$ and $\mathrm{MBH}$-acetate $\mathbf{2 a}$ as the model substrates and $10 \mathrm{~mol} \%$ of C1-C10 as the catalysts (Fig. 2 and Table 1). When the reaction was carried out in THF using (-)-sparteine $\mathbf{C 1}$ as the catalyst, complete conversion was observed in $1 \mathrm{~h}$ to give the product in $80 \%$ yield, but, unfortunately, there was no selectivity at all (entry 1 ). This prompted us to switch to bifunctional catalysts with a Lewis basic moiety which can deprotonate 1,3-dicarbonyl $\mathbf{1}$ and a Bronsted acid moiety which can activate $\mathrm{MBH}$ acetate 2 . Thus cinchona-derived thiourea catalysts $\mathbf{C 2}-\mathbf{C 8}^{20}$ were screened (entries 2-10). Although product 4a was isolated in good to excellent yield (78-94\%), to our dismay, the selectivity remained low to moderate (24-69\% ee).

At this juncture, we turned to quinine-squaramide catalysts C9-C10, ${ }^{21}$ in anticipation that their stronger H-bonding capability vis-à-vis their thiourea counterparts C2-C8 would enhance the selectivities. Accordingly, we were pleased to note a dramatic rate acceleration and an equally dramatic rise in the enantioselectivity when squaramide C9 was employed (90\% yield, 92\% ee, 15 min, entry 11). A slight improvement in the yield with a marginal drop in the selectivity was observed in the presence of squaramide C10 (92\% yield, 86\% ee, 15 min, entry 12). After zeroing in on the catalyst, several solvents were screened at room temperature with the aim of further improving the selectivity (entries 13-19). Thus the ee remained $\geq 90 \%$ in solvents such as $\mathrm{CHCl}_{3}, \mathrm{CH}_{2} \mathrm{Cl}_{2}, \mathrm{DCE}, \mathrm{CH}_{3} \mathrm{CN}$ and EtOAc (entries 13-15, 17 and 18),

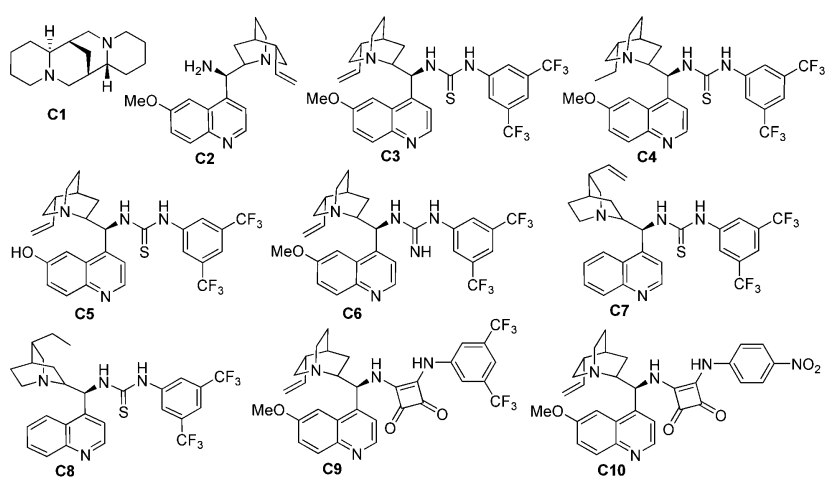

Fig. 2 Catalysts screened.
Table 1 Optimization of catalysts and solvents ${ }^{a}$

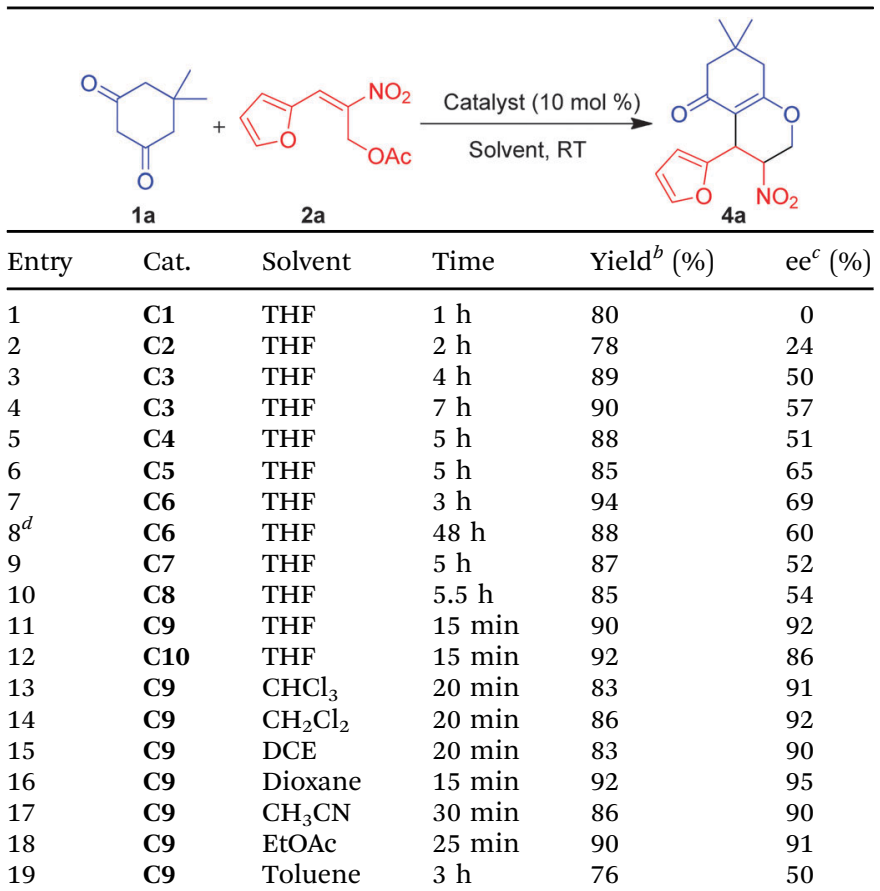

${ }^{a}$ Optimizations were done with $0.11 \mathrm{mmol}$ of $1 \mathrm{a}, 0.1 \mathrm{mmol}$ of $2 \mathrm{a}$ and $0.01 \mathrm{mmol}$ of catalyst $\mathrm{C}$ in $0.5 \mathrm{~mL}$ solvent under $\mathrm{N}_{2} .{ }^{b}$ After silica gel column chromatography. ${ }^{c}$ Determined by chiral HPLC using an AD-H column for the major diastereomer (dr, determined by ${ }^{1} \mathrm{H}$ NMR spectroscopy, were in the range of $88: 12$ to $91: 09) .{ }^{d}-40{ }^{\circ} \mathrm{C}$.

but dropped in toluene (50\%, entry 19$)$ while maintaining the yields in the range of $76-90 \%$. However, a considerable improvement in the ee (to 95\%) was observed in 1,4-dioxane (92\% yield, 15 min, entry 16). Finally, 10 mol\% of catalyst C9 in 1,4-dioxane at rt was identified as the best condition for our further reactions.

Initially, the scope of 1,3-dicarbonyls was investigated under the above optimized conditions using $\mathrm{MBH}$ acetate $\mathbf{2 a}$ as the representative substrate (Table 2). The results with cyclohexane1,3-dione $\mathbf{1 b}$ were inferior to what we obtained with dimedone 1a (4b: 81\% yield, 88 : $12 \mathrm{dr}$, 92\% ee). Cyclic $\beta$-keto ester hydroxy

Table 2 Screening of 1,3-dicarbonyls $\mathbf{1}^{a-c}$
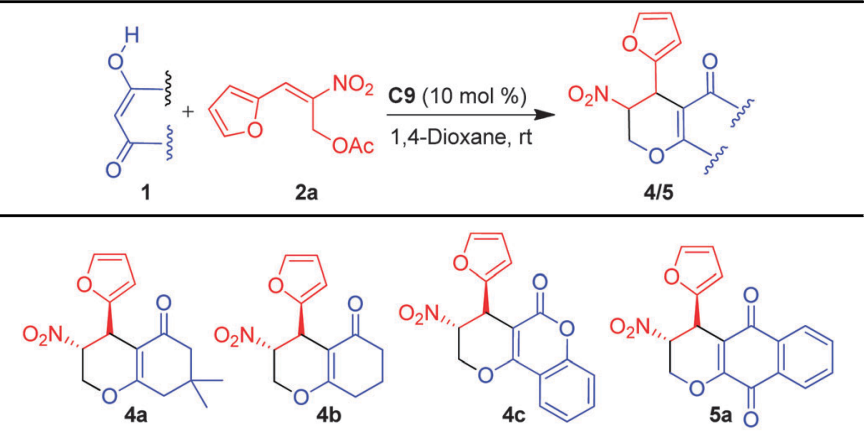

$25 \min , 92 \% \quad 20 \min , 81 \% \quad 60 \min , 93 \%$

dr $91: 9$, ee $95 \% \quad$ dr $88: 12$, ee $92 \% \quad$ dr $99: 1$, ee $49 \% \quad$ dr $98: 2$, ee $>99 \%$

${ }^{a}$ Yields after silica gel column chromatography. ${ }^{b} \mathrm{dr}$ was determined by ${ }^{1} \mathrm{H}$ NMR spectroscopy of the crude product and ee (for the major diastereomer) by chiral HPLC using an AD-H column. ${ }^{c}$ All the reactions were carried out with $0.55 \mathrm{mmol}$ of $1 \mathrm{a}, 0.5 \mathrm{mmol}$ of $2 \mathrm{a}$ and $0.05 \mathrm{mmol}$ of $\mathbf{C 9}$ in $2.5 \mathrm{~mL}$ 1,4-dioxane under $\mathrm{N}_{2}$. 
Table 3 Scope of $\mathrm{MBH}$ acetates $2^{a-d}$

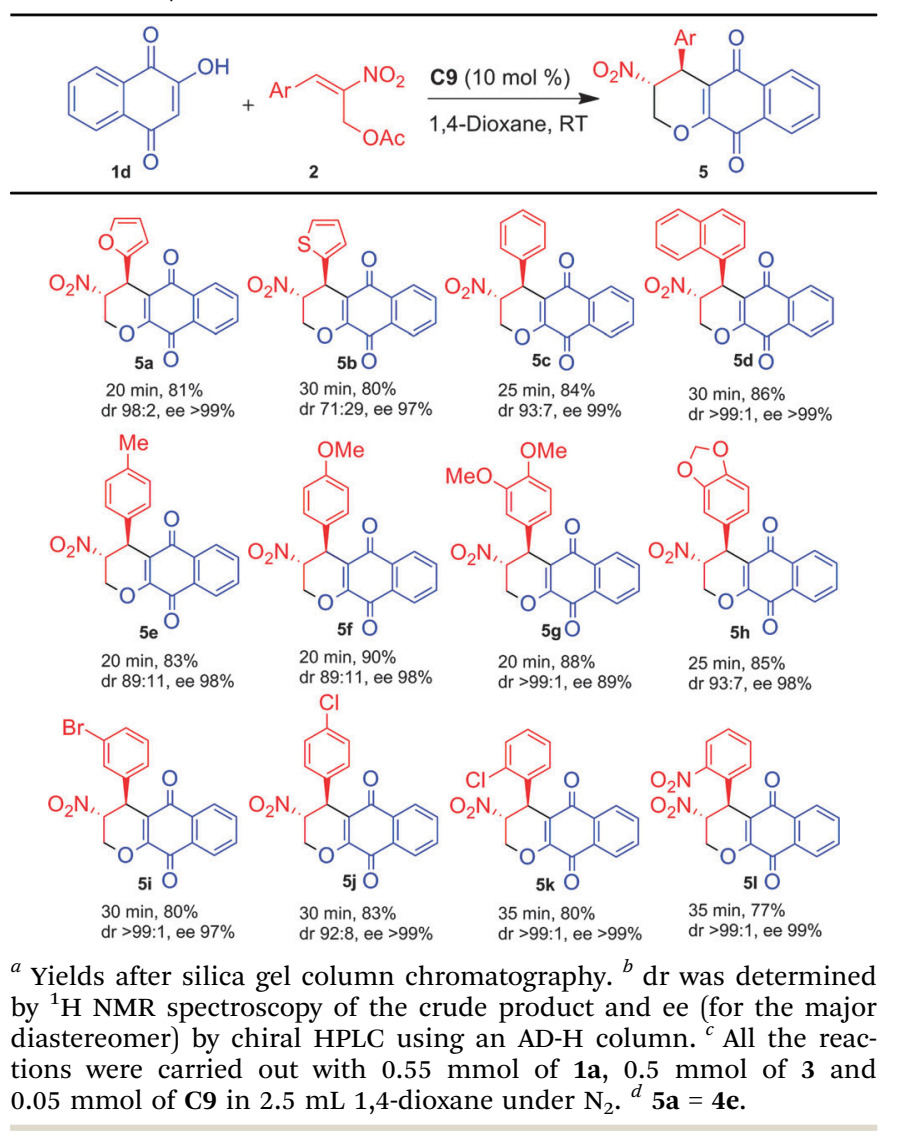

chromenone 1c also reacted with $\mathrm{MBH}$ acetate $2 \mathrm{a}$ to afford product $4 \mathbf{c}$ in excellent yield (93\%). However, while the diastereoselectivity was high (99:1), the enantioselectivity was moderate ( $49 \%$ ee). Finally, to our delight, lawsone 1d turned out to be an excellent binucleophile, providing product 5a in high yield (81\%) and with impressive selectivities (98:2 dr, $>99 \%$ ee).

Having achieved nearly absolute selectivities using lawsone 1d as the binucleophile, we proceeded to investigate the scope of MBH acetates 2 under the optimized conditions (Table 3). As in the case of 2-furyl MBH acetate $2 \mathbf{a}$, the thienyl analog $\mathbf{2 b}$ also reacted well with lawsone $\mathbf{1 d}$ to afford pyranonaphthoquinone $\mathbf{5 b}$ in high $(80 \%)$ yield and enantioselectivity ( $97 \%$ ee), though with moderate diastereoselectivity $(71: 29 \mathrm{dr})$. The MBH acetates $\mathbf{2 d}, 2 \mathbf{j}$, and $\mathbf{2 k}$, with fused or chloro-substituted aromatic rings, reacted with lawsone $\mathbf{1 d}$ to give products $\mathbf{5 d}, \mathbf{5 j}$, and $\mathbf{5 k}$ with high diastereo- $(\geq 92: 8)$ and enantioselectivities $(\geq 99)$. The yields (80-90\%) and enantioselectivities (97 to $>99 \%$ ) were excellent for dihydropyranonaphthoquinones $\mathbf{5 c}, \mathbf{5 e}, \mathbf{5 f}, \mathbf{5 h}$, and $\mathbf{5 i}$, with unsubstituted or para-substituted aromatic rings, though there was a marginal drop in the diastereoselectivities (89:11 to $93: 7)$. High yield (88\%) and absolute diastereoselectivity (>99:1) with marginally lower enantioselectivity ( $89 \%$ ee) for product $5 \mathbf{g}$ were observed in the case of $\mathrm{MBH}$ acetate $\mathbf{2} \mathbf{g}$ with multiple electron donating substituents.

The structure and relative configuration of the products were determined by detailed spectral analysis (see the ESI $\$$ ) which were further confirmed by single crystal X-ray analysis of
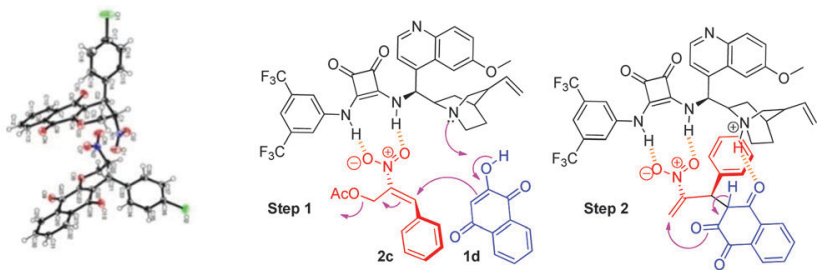

Fig. 3 X-ray structure of $\mathbf{5} \mathbf{j}$ and the proposed mechanistic model.

a representative compound 5 j (Fig. 3, also see the ESI ). Furthermore, the absolute configuration of $5 \mathbf{j}$ was also assigned $(3 R, 4 S)$ based on X-ray data and that of the analogs 4 and 5 by analogy. A plausible mechanism, using lawsone 1d and MBH acetate $2 \mathbf{c}$ as the representative substrates, is outlined in Fig. 3. The first step is initiated by deprotonation of $\mathbf{1 d}$ by the tertiary amine of the quinuclidine moiety resulting in an enolate. The enolate then adds to $\mathrm{MBH}$ acetate $\mathbf{2 c}$ from the $S i$ face in a Michael fashion, which is facilitated by activation of the nitro group by double $\mathrm{H}$-bonding with the squaramide moiety of the chiral catalyst, leading to elimination of the acetate in the overall $\mathrm{S}_{\mathrm{N}} 2^{\prime}$ reaction. In the second step, the enolate generated by H-bonding of the carbonyl group with the protonated quinuclidine moiety adds to the nitroalkene activated by the squaramide moiety from the $R e$ face in a 6-endo-trig intramolecular oxa-Michael fashion, giving rise to the desired dihydropyran. Our solvent screening (Table 1, entries 11, 13-19) suggests that polar aprotic solvents (e.g. dioxane) that do not interfere with the catalyst are suitable for this transformation.

Our methodology was applicable to the gram scale reaction as well with a catalyst loading as low as $1 \mathrm{~mol} \%$ (Scheme 2, see also the ESI ). Addition of $696 \mathrm{mg}$ (4 mmol) of lawsone 1d to $0.884 \mathrm{~g}$ of $\mathrm{MBH}$ acetate $2 \mathrm{c}$ or $1.004 \mathrm{~g}$ of $2 \mathrm{f}(4 \mathrm{mmol})$ in the presence of $30 \mathrm{mg}(0.04 \mathrm{mmol}, 1 \mathrm{~mol} \%)$ of catalyst $\mathbf{C} 9$ afforded $1.110 \mathrm{~g}$ (3.64 mmol, 83\%) of nitroquinone $5 \mathrm{c}$ or $1.168 \mathrm{~g}$ $(3.20 \mathrm{mmol}, 80 \%)$ of $\mathbf{5 f}$ without any appreciable change in the diastereo- and enantioselectivities. The nitro group of quinones $\mathbf{5 c}$ and $\mathbf{5 f}$ could be transformed to the amino group using $\mathrm{NiCl}_{2} \cdot 6 \mathrm{H}_{2} \mathrm{O} /$ $\mathrm{NaBH}_{4}$ to afford aminoquinones $\mathbf{6 c}$ and $\mathbf{6 f}$. While $\mathbf{6 f}$ was isolated in

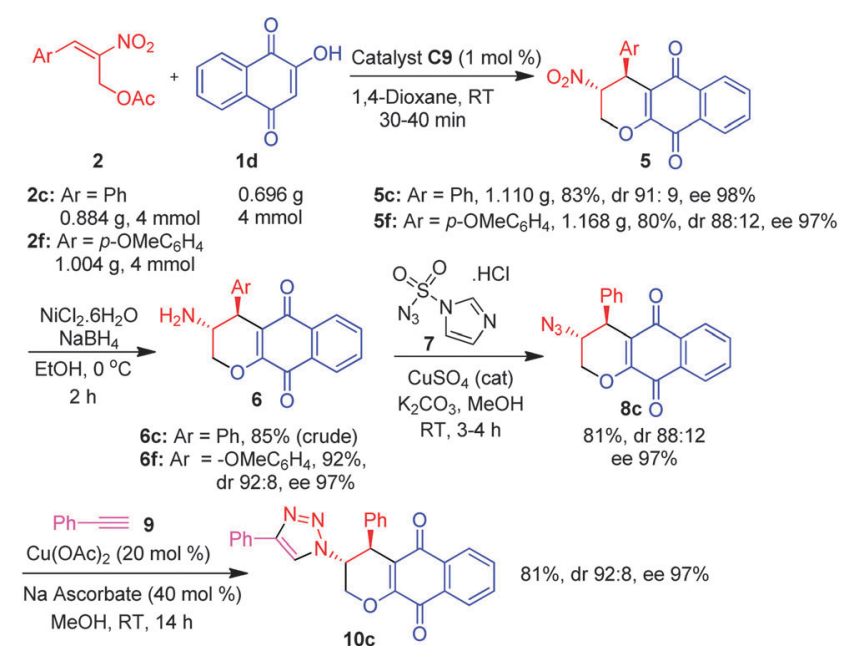

Scheme 2 Synthetic applications of $\alpha$-lapachones 5 . 
excellent yield (92\%) without any loss of stereochemical integrity (dr $92: 8$, ee $97 \%$ ), crude $6 \mathbf{c}$, due to its instability, was treated with azide 7 to furnish azidoquinone $8 \mathrm{c}$ in high yield (81\%) and selectivities (dr 88:12, ee 97\%). Finally, the click reaction ${ }^{22}$ of azidoquinone $8 \mathrm{c}$ with phenylacetylene 9 provided triazole $10 \mathrm{c}$ in high yield (81\%) and selectivities (dr 92 : 8, ee 97\%).

Due to the potential trypanocidal activity of the lapachone derivatives (vide supra), we evaluated compounds $\mathbf{5 a}-\mathbf{5 g}$ and $\mathbf{5 i - 5 1}$ against the infective bloodstream form of Trypanosoma cruzi, the etiological agent of Chagas disease. Benznidazole $\left(\mathrm{IC}_{50} / 24 \mathrm{~h}=103.6 \pm 0.6 \mu \mathrm{M}\right){ }^{23}$ the standard anti-T. cruzi drug, was used as the positive control. Preliminary experiments showed that our compounds at concentrations of up to $0.5 \%$ in DMSO had no deleterious effects on the parasites. The compounds evaluated were not active against $T$. cruzi with $\mathrm{IC}_{50}$ values $>1000.0 \mu \mathrm{M}$ (see the ESI ). Possible enhancement of trypanocidal activity via structural modifications and studies on other biological activities of $\alpha$-lapachones 5 are being currently investigated in our laboratories and will be reported in due course.

In conclusion, a chiral squaramide-catalysed cascade reaction of 1,3-dicarbonyl compounds, including 2-hydroxy-1,4-naphthoquinone (lawsone), with Morita-Baylis-Hillman acetates of nitroalkenes affords pyrans and pyranonaphthoquinones ( $\alpha$-lapachones) in high yields and excellent diastereo- and enantioselectivities. The transformation which involves an $\mathrm{S}_{\mathrm{N}} 2^{\prime}$-intramolecular oxa-Michael addition sequence is amenable for scale-up even with a very low catalyst loading ( $1 \mathrm{~mol} \%$ ) without an appreciable loss in yield or selectivity. The multi-step transformation of a representative product to a naphthoquinonebased 1,2,3-triazole via nitro group reduction, conversion to azide and click reactions as well as preliminary evaluation of the $\alpha$-lapachones for trypanocidal activity have been carried out.

INNN thanks DST India for financial assistance. DKN thanks CSIR India for a senior research fellowship. RFSMB and ENSJ thank CNPq and CAPES Brazil.

\section{Notes and references}

1 Selected recent reviews: (a) A. V. Pinto and S. L. de Castro, Molecules, 2009, 14, 4570; (b) Y. Kumagai, Y. Shinkai, T. Miura and A. K. Cho, Annu. Rev. Pharmacol. Toxicol., 2012, 52, 221; (c) S. L. de Castro, F. S. Emery and E. N. da Silva Júnior, Eur. J. Med. Chem., 2013, 69, 678; (d) C. O. Salas, M. Faundez, A. Morello, J. D. Maya and R. A. Tapia, Curr. Med. Chem., 2011, 18, 144; (e) P. Singh, V. Krishna, P. Khandelwal, K. K. Sharma and M. C. Sharma, J. Indian Chem. Soc., 2010, 87, 85.

2 For an article: M. O. F. Goulart, C. L. Zani, J. Tonholo, L. R. Freitas, F. C. de Abreu, A. B. Oliveira, D. S. Raslan, S. Starling and E. Chiari, Bioorg. Med. Chem. Lett., 1997, 7, 2043.

3 P. Krishnan and K. F. Bastow, Biochem. Pharmacol., 2000, 60, 1367.

4 C. Salas, R. A. Tapia, K. Ciudad, V. Armstrong, M. Orellana, U. Kemmerling, J. Ferreira, J. D. Maya and A. Morello, Bioorg. Med. Chem., 2008, 16, 668.
5 A. Fujiwara, T. Mori, A. Lida, S. Ueda, Y. Hano, T. Nomura, H. Tokuda and H. Nishino, J. Nat. Prod., 1998, 61, 629.

6 T. T. Guimarães, M. C. F. R. Pinto, J. S. Lanza, M. N. Melo, R. L. do Monte-Neto, I. M. M. de Melo, E. B. T. Diogo, V. F. Ferreira, C. A. Camara, W. O. Valença, R. N. de Oliveira, F. Frézard and E. N. da Silva Júnior, Eur. J. Med. Chem., 2013, 63, 523.

7 S. Pethuan, P. Duangkaew, S. Sarapusit, E. Srisook and P. Rongnoparut, J. Med. Entomol., 2012, 49, 993.

8 T. Kimachi, E. Torii, R. Ishimoto, A. Sakue and M. Ju-ichi, Tetrahedron: Asymmetry, 2009, 20, 1683.

9 (a) W.-M. Zhou, H. Liu and D.-M. Du, Org. Lett., 2008, 10, 2817; (b) W. Yang and D.-M. Du, Adv. Synth. Catal., 2011, 353, 1241; (c) R. Wu, X. Chang, A. Lu, Y. Wang, G. Wu, H. Song, Z. Zhou and C. Tang, Chem. Commun., 2011, 47, 5034; (d) E. Zhou, B. Liu and C. Dong, Tetrahedron: Asymmetry, 2014, 25, 181; (e) P. Kasaplar, C. Rodriguez-Escrich and M. A. Pericas, Org. Lett., 2013, 15, 3498; $(f)$ B. V. S. Reddy, M. Swain, S. M. Reddy and J. S. Yadav, $R S C A d v$., 2013, 3, 8756. For catalytic asymmetric conjugate addition of other 1,3-dicarbonyls to nitroalkenes, reviews: $(g)$ T. Ikariya and I. D. Gridnev, Top. Catal., 2010, 53, 894; (h) T. Ikariya and I. D. Gridnev, Chem. Rec., 2009, 9, 106; (i) O. M. Berner, L. Tedeschi and D. Enders, Eur. J. Org. Chem., 2002, 1877.

10 G. Zhang, Y. Wang, W. Zhang, X. Xu, A. Zhong and D. Xu, Eur. J. Org. Chem., 2011, 2142.

11 Y.-F. Wang, W. Zhang, S.-P. Luo, G.-C. Zhang, A.-B. Xia, X.-S. Xu and D.-Q. Xu, Eur. J. Org. Chem., 2010, 4981.

12 T. Liu, Y. Wang, G. Wu, H. Song, Z. Zhou and C. Tang, J. Org. Chem., 2011, 76, 4119.

13 Via addition of hydroxynaphthoquinone to $(a)$ enals catalysed by diarylprolinol ether: M. Rueping, E. Sugiono and E. Merino, Angew. Chem., Int. Ed., 2008, 47, 3046. (b) $\beta, \gamma$-Unsaturated $\alpha$-ketoesters catalysed by chiral thiourea: Y. Gao, Q. Ren, S.-M. Ang and J. Wang, Org. Biomol. Chem., 2011, 9, 3691.

14 D. K. Nair, S. M. Mobin and I. N. N. Namboothiri, Tetrahedron Lett., 2012, 53, 3349.

15 D. K. Nair, S. M. Mobin and I. N. N. Namboothiri, Org. Lett., 2012, 14, 4580 .

16 T. Kumar, S. M. Mobin and I. N. N. Namboothiri, Tetrahedron, 2013, 69, 4964.

17 Cyclopentene: $(a)$ L. F. Yeh, S. Anwar and K. Chen, Tetrahedron, 2012, 68, 7317; (b) furans and pyrans: W. Y. Huang, Y. C. Chen and K. Chen, Chem. - Asian J., 2012, 7, 688. (c) Arenofurans: S. Anwar, W.-Y. Huang, C.-H. Chen, Y.-S. Cheng and K. Chen, Chem. - Eur. J., 2013, 19, 4344.

18 M. Yaqub, C. Y. Yu, Y. M. Jia and Z. T. Huang, Synlett, 2008, 1357. 19 Asymmetric synthesis of bicyclic skeletons via pyrrolidine-thiourea catalysed addition of cycloalkanones to $\mathrm{MBH}$ acetates $2(\mathrm{E}=\mathrm{H})$ : C. L. Cao, Y.-Y. Zhou, J. Zhou, X.-L. Sun, Y. Tang, Y.-X. Li, G.-Y. Li and J. Sun, Chem. - Eur. J., 2009, 15, 11384.

20 Selected reviews on chiral thiourea catalysis: $(a)$ S. J. Connon, Chem. Commun., 2008, 2499; (b) A. G. Doyle and E. N. Jacobsen, Chem. Rev., 2007, 107, 5713; (c) H. Miyabe and Y. Takemoto, Bull. Chem. Soc. Jpn., 2008, 81, 785; (d) B. List, Top. Curr. Chem., 2010, 291; (e) Synthesis, ed. E. M. Carreira, 2011, Issue 12 (Special Issue on Organocatalysis); $(f)$ S. B. Tsogoeva, Eur. J. Org. Chem., 2007, 1701; (g) Y. Takemoto, Org. Biomol. Chem., 2005, 3, 4299.

21 Chiral squaramide catalysis: (a) J. P. Malerich, K. Hagihara and V. H. Rawal, J. Am. Chem. Soc., 2008, 130, 14416; (b) Y. Zhu, J. P. Malerich and V. H. Rawal, Angew. Chem., Int. Ed., 2010, 49, 153.

22 V. V. Rostovtsev, L. G. Green, V. V. Fokin and K. B. Sharpless, Angew. Chem., Int. Ed., 2002, 41, 2596.

23 E. N. da Silva Júnior, R. F. S. Menna-Barreto, M. C. F. R. Pinto, R. S. F. Silva, D. V. Teixeira, M. C. B. V. Souza, C. A. de Simone, S. L. de Castro, V. F. Ferreira and A. V. Pinto, Eur. J. Med. Chem., 2008, 43, 1774 . 